\title{
The Language Laboratory
}

Joseph H. Sheehan

Editors Note: The following article constitutes a segment of a larger work intended for inclusion in a handbook prepared for the National Association of Foreign Student Advisors. It appears here with permission of the author.

\section{DEFINITIONS}

Learning Resources (LR) consist not only of people and places but also hardware, e.g., overhead projectors, TV, etc., and software, e.g., texts, tapes, etc.

\section{PURPOSES}

The administrators of a program must be sure that the hardware and software are appropriate and effective for their programs. The professional staff, under the guidance of the administration, should select those resources which effectively and efficiently help the student attain the instructional objectives of the program. The teacher is the mediator between the student's present competency and the above mentioned objectives, and prescribes the media (software and hardware) to be used by the class and/or the individual student.

Learning resources are not limited to the classroom and to the teachers' and students' use of the overhead projectors, tape recorders, etc. there.

\section{LEARNING LABORATORIES}

In the same way that the physical, social, and business sciences provide laboratories for students to learn, so too, the language program can offer laboratories where students (as a class or individuals) go to be introduced to new subject matter and to reinforce and extend their learning.

\section{LEARNING LABORATORY}

The learning laboratory consists of software and usually hardware. The most common is called the language laboratory.

\section{BROADCAST/LIBRARY}

The language laboratory in its basic elements consists of a listening system where a class works as a unit by hearing the same program, the broadcast system, or where students work on separate programs as individuals, the library system. Beginning and low intermediate students seem to benefit more from the broadcast method because they can be more easily guided, monitored, and evaluated if they are on the same task. 


\section{LEVELS}

The hardware usually consists of three functional levels where the student listens with earphones (Audio Passive-AP), uses a headset and thus hears himself electronically (Audio Active-AA) or uses a headset, records his utterances and responses, replays them and compares his work with the model and/or correct answer (Audio Active Comparative$A A C)$. For further details, Stack's book is suggested.

\section{CONSULTANTS}

Once the system, broadcast or library, is decided on, one must select the hardware. Unless you are an expert do not do it by yourself. Library media specialists are usually not experts in language laboratories but rather in learning laboratories. The foreign language laboratory director often is a technician or a language teacher. Look for one who is both. Ideally one would locate a consultant or director who is qualified as an ESL/FL teacher and a learning Laboratory director.

One can request a consultant from: Professor Sam Burggraaf, Executive Secretary, NALLD, David O. McKay Institute, W-162 Stadium, Brigham Young University, Provo, Utah 84602. NALLD has over 500 members in over 17 countries. The consultant can help the administrator decide on the relevancy of the laboratory choices, e.g., half track vs. quarter track, portable vs. fixed laboratory, cassette vs. open reel, library vs. broadcast, which brands, kind of furniture, location of laboratory and positions within it, etc. He can indicate where various laboratories can be seen in operation.

\section{HARDWARE}

In general, expect to pay approximately $\$ 1,000$ per student position for a new language laboratory. To get acquainted with the possible hardware, borrow from an AV specialist a copy of the current AudioVisual Equipment birectory, which gives list prices as well as information on equipment. Expect a discount on the larger systems.

\section{RATIONALE}

Evaluations of the traditional language laboratory can be reviewed by reading Appendix VII of Chastain and updating that with Green's book on the York Study. For up-to-date rational for justifying the laboratory, see the bibliography below giving special note to Rivers' paper on speech perception'.

The utilization of the equipment and often the selection of the equipment should be influenced by the objectives of the program and the software to be used.

'Audio in the 1970's, Proc. of DLI Working Conference, 19-21 May 1971 (Washington: Defense Language Institute, n.d.), pp. 27-44. 


\section{SOFTWARE}

Many teachers feel there is a lack of "good" software if not in texts then in laboratory materials. As can be seen from the catalogs of tape suppliers advertising in the TESOL Quarterly, most tapes are text bound. When texts are selected for a program one must listen to the tapes and have them evaluated not only for content but for distortion, wow and flutter, length, rate of speech, American vs. non-American English, etc. Do not select a text for which the publisher will not give written permission to duplicate the recordings in the manner that is beneficial to your program, e.g., student copies. One may consult AECT's publication on Copyright, and for an updating and reasonable interpretation consult articles by Jerome Miller in such publications as the NALL Joumal. Texts should be selected with the intention of using them more than one semester and so that they are worked into the program and become familiar to the staff. As a-result, the material's effectiveness and appropriateness can be evaluated over a period of time. The tape scripts and teacher's manuals should be purchased so the software can be used as the authors intended. If there is a new staff, they should not be allowed to make tapes for the laboratory. Either they use exercises from a text without the publishers' permission and academic justification or they create their own materials without the realization that material writing is a special skill for which they may not have either the talent or the training. If, however, the above is not true, Higgins' text could be of value.

\section{UTILIZATION}

The next step is to determine the role of the software. The role depends on the answers to some questions. Is the media to be introduced in the classroom or the laboratory? What is the role of the software? Is it to prepare the student for a class, to reinforce what he has been taught? Consult, among others, E. Turner's "Correlation" and J. Turner's Programming.

The above is an outline of the hardware, software and utilization of the traditional language laboratory. Currently these laboratories are being expanded and/or augmented by other non-group media for the individual e.g. the filmstrip projector, TV, card reader (Language Master), speech compressor/expander, computer terminal, etc. These media may often be used in conjunction with the language laboratory or may be a separate learning resource laboratory where students may work on individual tasks including programmed texts. One kind of laboratory facility, an English Skills Laboratory, is described by Alice Pack who states that its primary purpose is ". . . to provide assistance in developing and reinforcing specific and/or general English skills on an individual basis for any student . . . who desires or requires it." 
The operation of the learning laboratroy, both the language laboratory and the individual media laboratory, depends not only on the guidelines set by the administration, e.g., how many hours a week, cost effectiveness, space, schedule, discipline, attendance, etc., but also on the staff and selection of that staff.

\section{PERSONNEL}

The selection of a consultant and, possibly a language laboratory director was mentioned above. Whatever systems are used there should be a supervisor who is qualified in terms of an analysis of what is required. Often it is a director who should, at minimum, be technically knowledgeable and professionally competent in administration and language learning-a language learning technology specialist-with a background in ESL/ FL. To put a student-even a graduate student-in charge can court disaster for the program and for him. (The current Foreign Minister of Iran was the laboratory supervisor when a graduate student at Georgetown University.) The selection of software should be done by someone knowledgeable with media and the ESL subject matter. The supervisor should be responsible for the training of the laboratory staff but not necessarily for its education. Laboratory monitors/instructors are usually teachers, graduate students in the field or undergraduates who need a job. Some materials require use by a qualified teacher-others may be administered by non-professional monitors, but in all cases a professional should make the assignments and evaluate the effectiveness and efficiency of the media. Many self-instructional ESL materials are self-correcting and have answers supplied in the text or workbook. Other software may require a personal evaluation of the student's response to a task, e.g., pronunciation, by a monitor.

\section{EVALUATIONS}

Some media have built-in means of evaluation such as a language laboratory which broadcasts the task to the student, turns on the student's machine to record only his response and turns it off within a certain time frame. Some systems require the student to pass a criterion test and be programmed according to the results.

The staff in the laboratory should have a means to feedback the students' progress reports to the person assigning the task which is usually the classroom teacher who is coordinating the class'/student's laboratory work with the class work or a student's particular need.

There are several trends in Listening Resources. As a guideline one could follow the old French clerical maxim: Be not the first by whom the new is tried nor the last by whom the old is laid aside. 


\section{MEDIA DEVELOPMENTS}

New laboratory consoles have many features such as "teacher logic" programming or the facility of two people monitoring different students. But many features are optional and should not be included unless it can be strongly justified. The more features you have the greater the possibility of problems.

A consultant can advise what is useless, questionable, or necessary for your program.

\section{VIDEO}

Some laboratories now include video, e.g., viewing a videotape on cultural differences, recording the sound track, writing answers to questions based on the videotape, etc. Until recently the "ESL Video Newsletter" was an excellent source of materials, utilization, and review. It is reported that its successor may be obtained from the editor, Language Video International, 11 North Hamilton Street, Ypsilanti, Michigan 48197. Successful telecourses in ESL are, to say the least, rare. There are, however, videotapes which demonstrate nonverbal aspects of communication as well as paralinguistic cues. If the video elicits an oral response from the student, then at least an audio active system should be used in the laboratory so that he may hear his response.

\section{RATE CONTROLLED SPEECH}

Control of the rate of speech has been an almost insurmountable problem until the technological spin-off from the U.S. Space Program. With pitch control it is possible to have intelligible speech which is varied in speed; the "grumble" and the "chipmunk" distortions are removed allowing for expanded speech about half normal speech to compressed speech about two and a half times normal speech. A pioneering study about second language acquisition by Sr. Etienne Flaherty ${ }^{3}$ demonstrates the effect of speech expansion on listening comprehension performance.

The seminal work by Robert W. Bruns for time-compressed speech in second language acquisition is of particular import because it was done in an intensive English program. ${ }^{4}$ Occasionally articles appear in Foreign Language Annals updating this area.

\section{VIDEO DISC}

The video disc is one of the most recent developments to come from Europe. A disc similar to a phonograph record is played on a player which allows random access to any part of the record. Some systems can store 50,000 slide pictures or frames on a record and display each one at a time or similar to a movie. The playing of the record produces a video image with sound. To produce one's own program is difficult and very expensive and there seems to be little immediate advantage to ESL in the video disc. 


\section{COMPUTERS}

Computer Based Education (CBE) may be viewed as Computer Assisted Instruction (CAI) or Computer Managed Instruction (CMI). In CAl the software is the computer program and the hardware the computer terminal. The only computer ESL program known to this author is PLATO (Programmed Logic for Automated Teaching Operations). In CMI the software consists of the computer program and other software as well as hardware of other media. The computer directs the student to other media, tests him, evaluates the results and programs him to his next step. The Center for English as a Second Language at the University of Arizona has been working on the problem of interfacing the system with audio capability thus allowing the scope of $\mathrm{CAl}$ to be expanded. Further information about PLATO can be obtained by writing to: Control Data Education Company, HQAO2J, Box 0, Minneapolis, Minnesota 55440.

For many programs these last mentioned features and developments may seem far in the future. They are not. Technology has outrun the teacher and awaits further requests. Technology is there for the asking, but the teacher and administrator must ask. The learning laboratory is more than hardware and software. To benefit from it the student must:

(1) be cognitively and affectively prepared by the classroom teacher,

(2) know what he is expected to do,

(3) work on materials that are appropriate to his level.

(4) work on materials that are a means to obtaining the instructional goals set forth by the teacher, and

(5) be evaluated.

If the above is done then it is not unreasonable to expect that a student could:

(1) be aware of voices and dialects other than those of his teacher,

(2) develop his echoic memory,

(3) take responsibility for doing a task thoroughly,

(4) develop an awareness of what is correct,

(5) apply what he has learned in the classroom to new tasks,

(6) extend what has been learned in the classroom,

(7) make the grapheme-phoneme correspondence recognition more skillfully, and

(8) increase comprehension.

3"The Effect of Time Expansion on Listening Comprehension of High School Students in Second Year French Classes," The Center for RateControlled Recordings Newsletter, Vol. 9, No. 6, November/December 1975.

4"A Study of the Effects of Practice in Time-Compressed Speech Listening Upon Aurol Comprehension Levels of Second Language Learners," Diss. University of Colorado 1978. 
Long before there were laboratories students learned ESL but maybe it can be made more efficient and effective.

Mr. Joseph H. Sheehan, President

National Association of Learning Laboratory Directors

Language \& Culture Center, Dept. of English

University of Houston

Houston, TX 77004

(713) $749-2716$

\section{BIBLIOGRAPHY}

Association for Educational Communications and Technology. Copyright and Educational Media: A Guide to Fair Use and Permissions Procedures Washington, D.C.: AECT, 1977.

Audio-Visual Language Association. Audio-Visual Language Journal.

Bulletin Cila: Organe De La Commission Interuniversitaire Suisse De Linguistique Appliquee. Neuchatel, Switzerland: Institut de Linguistique

Bruns, Robert W. "A Study of the Effects of Practice in Time-Compressed Speech Listening upon Aural Comprehension Levels of Second Language Learners." Diss. University of Colorado 1978.

Chastain, Kenneth. The Development of Modern Language Skills: Theory ....to Practice. New York: The Center for Curriculum Development 1971.

Communication and Language Arts Division-Brigham Young University. TESL (Teaching English as a Second Language) Reporter.

Dakin, Julian. The Language Laboratory and Language Learning. London: University of London Press, 1968.

Davison, Walter F. The Language Laboratory: A Bibliography, 1950-1972. Pittsburgh: University Center for International Studies and the English Language Institute, 1973.

\section{Foreign Language Annals.}

Green, Peter S., ed. The Language Laboratory in School: Performance and Prediction. New York: Oliver \& Boyd, 1975.

Higgins, J. J. A Guide to Language Laboratory Material Writing. Englewood Cliffs, N.J.: Educational Technology Publications, 1969. 
Hutchinson, Joseph C. and June O. "Criteria for Selecting Types of Foreign Language Laboratory Systems." ERIC: Focus Reports on the Teaching of Foreign Languages. 1970.

Jones, Judith, ed. The Videolog: Programs for General Interest and Entertainment 1979.

Medley, Frank W. "Maintenance of the Language Laboratory." ERIC: Focus Reports on the Teaching of Foreign Languages.

NALLD Journal.

National Center for Audio Tapes 1974-76 Catalog.

Proceedings of DLI Working Conference. Audio in the 1970's: (Role and Potential in Language Training). Washington, D.C.: Headquarters, Defense Language Institute, 1971.

Stack, Edward M. The Language Laboratory and Modern Language Teaching. 3rd ed. London: Oxford University Press, 1971.

ERIC: Focus Reports on the Teaching of Foreign Languages.

System: The International Journal of Educational Technology and Language Learning Systems.

TESOL Quarterly.

The Audio-Visual Equipment Directory. Fairfax, Va.: National Audio-Visual Association.

The Center for Rate-Conrtolled Recordings News Letter.

Turner, E. Daymond, Jr. "Correlation of Language Class and Language Laboratory." ERIC: Focus Reports on the Teaching of Foreign Languages. 1969.

Turner, John D., ed. Programming for the Language Laboratory. London: University of London Press, 1968.

Wisconsin Department of Public Instruction. Field Check Manual for Language Laboratories. 1964.

Coming in the next issue of the NALLD JOURNAL Vol. 15 No 2 Articles on Visual Metaphors and Compositions, Research Trends in Rate Controlled Speech, Learning Capabilities of Retarded Children.

Plus OFF-THE-AIR Editor Ed Richmond continues the discussion of Shortwave Antennas

and MORE! 